\title{
HUBUNGAN DUKUNGAN KELUARGA DENGAN TINGKAT KECEMASAN \\ PADA PASIEN GAGAL GINJAL KRONIS YANG MENJALANI HEMODIALISIS DI RSUD Dr. SOEHADI PRIJONEGORO SRAGEN
}

\author{
Ika Hayun Al Aziz, Sudiro \\ Kementerian Kesehatan Politeknik Kesehatan Surakarta Jurusan Keperawatan
}

\begin{abstract}
Family Support, Level Of Anxiety, Chronic Renal Failure, And Hemodialysis. Chronic kidney disease is a threat for human because the prevalency increase every years. Patient of chronic kidney disease with teraphy hemodialysis can cause psychological pressure pasca hemodialysis. One example of psychological pressure is anxiety. For decrease anxiety of patient with terapy hemodialysis need family support. Objectives To identity the relationship among family support with level of anxiety chronic renal failure of patients with therapy hemodialisis in Dr.Soehadi Prijonegoro Hospital. Methods Design of the research used descriptive analytic with cross sectional approach. The sampling method is total sampling. Instrument that used for measure level anxiety and family support is a questionnaire. Analysis for data used Kendall Tau. Ressearch result The majority of family support level is good with amount 38 (70,4\%). The majority of level anxiety is not anxiety with amount $38(70,4 \%)$. The result of kendall tau is $\alpha$ $: 0,000, \tau: 0,865$. Conclusion There is relationship between family support with level of anxiety chronic renal failure of patients with therapy hemodialysis.
\end{abstract}

Keywords : Family Support, Level Of Anxiety, Chronic Renal Failure, And Hemodialysis

\begin{abstract}
Abstrak: Dukungan Keluarga, Tingkat Kecemasan, Gagal Ginjal Kronik, Dan Hemodialisis. Gagal ginjal kronis merupakan ancaman bagi manusia karena dari tahun ke tahun mengalami peningkatan. Pada penderita gagal ginjal kronis yang menjalani hemodialisis dapat menyebabkan tekanan psikologis pasca menjalani terapi hemodialisis. Salah satu bentuk tekanan psikologis yaitu kecemasan, Untuk menurunkan kecemasan diperlukan dukungan keluarga. Tujuan Penelitian mengetahui hubungan dukungan keluarga dengan tingkat kecemasan pada pasien gagal ginjal kronis yang menjalani hemodialisis di ruang Hemodialisis di RSUD Dr.Soehadi Prijonegoro. Metode Penelitian Jenis penelitian yang digunakan adalah deskriptif analitik dengan pendekatan cross sectional. Metode pengambilan sampel adalah total sampling. Instrumen yang digunakan untuk mengukur tingkat kecemasan dan dukungan keluarga adalah kuesioner. Analisis data menggunakan uji Kendall Tau. Hasil Penelitian dukungan keluarga mayoritas baik sebesar 38 (70,4\%), Tingkat kecemasan mayoritas tidak cemas sebesar 38 (70,4\%), uji korelasi Kendall Tau didapatkan $\alpha: 0,000, \rho<$ $0,05, \tau: 0,865$. Terdapat hubungan antara dukungan keluarga dengan tingkat kecemasan pada pasien gagal ginjal kronis yang menjalalani terapi hemodialisis.
\end{abstract}

Kata Kunci : Dukungan Keluarga, Tingkat Kecemasan, Gagal Ginjal Kronik, Dan Hemodialisis 


\section{PENDAHULUAN}

Penyakit gagal ginjal kronis merupakan kerusakan struktur dan penurunan fungsi ginjal yang bisa berdampak pada ketidakmampuan ginjal untuk mempertahankan keseimbangan dan integritas tubuh. (Suwitra, 2007). Gagal ginjal kronis menjadi ancaman bagi masyarakat karena dari tahun ke tahun mengalami peningkatan. Tingginya angka kejadian penyakit gagal ginjal kronis di dunia sudah mencapai 26 juta orang. Diantaranya 20 juta penderita sudah masuk kedalam tahap akhir atau terminal. Menurut data Indonesia Renal Regristry (IRR) pada tahun 2012 korwil jateng 3073 pasien yang mengalami gagal ginjal kronis. Dari data yang diperoleh di ruang hemodialialisis RSUD Dr.Soehadi Prijonegoro Sragen pada tahun 2014 diperoleh pasien sebanyak 3734 pasien yang menjalani hemodialisis. Data pada tahun 2015 mengalami peningkatan sebanyak 4139 pasien.

Pasien gagal ginjal kronis harus menjalani terapi pengganti ginjal yaitu terapi hemodialisis atau transpalasi ginjal (Suwitra, 2007). Pada pasien yang menjalani terapi hemodialisis harus membatasi asupan cairan dan merubah gaya hidup yang lebih sehat. Pada penderita gagal ginjal kronis yang menjalani hemodialisis akan mengalami tekanan psikologis pasca menjalani terapi hemodialisis. Tekanan psikologis yang terjadi berupa : kecemasan, imsomnia, sulit berkonsentrasi, tidak nafsu makan, merasa putus asa berlebihan, dan hilangnya semangat hidup (Sheila, 2008). Tekanan psikologis terjadi karena pada pasien yang menjalani hemodialisis sangat tergantung pada alat, apabila penderita gagal ginjal kronis tidak menjalani terapi maka akan menjadi ancaman vonis mati yang tinggal menunggu waktu. Tekanan psikologis yang berupa kecemasan pada pasien gagal ginjal kronis yang menjalani hemodialisis terjadi karena kekhawatiran akan perasaan terganggu akan ketakutan atau aphrehensi terhadap sesuatu yang terjadi di masa depan, khawatir akan ditinggal sendirian dan berfikir akan segera mati, hal itu menjadi beban tersendiri bagi pasien yang menjalani hemodialisis (Jeffrey, 2006).

Berdasarkan hasil observasi dan wawancara yang dilakukan di RSUD Dr.Soehadi Prijonegoro Sragen terhadap 6 pasien didapatkan data bahwa 4 orang didampingi keluarga dan 2 orang datang sendiri tanpa didampingi oleh keluarga. Dari 4 orang yang di damping keluarga mengatakan merasa mudah sedih, merasa malu, gelisah, khawatir tentang hal hal yang sepele. Dari 2 orang yang tidak didampingi keluarga mengatakan merasa dirinya tidak ada perbedaan apabila ada atau tidak adanya anggota keluarga didekatnya, karena merasa sudah terbiasa dengan keadaan yang seperti ini.

Dari penjelasan di atas, penulis tertarik melakukan penelitian dengan judul "Hubungan dukungan keluarga dengan tingkat kecemasan pada pasien gagal ginjal kronis yang menjalani hemodialisis di ruang Hemodialisis RSUD Dr.Soehadi Prijonegoro Sragen".

\section{METODE PENELITIAN}

Jenis Penelitian ini merupakan penelitian kuantitatif non-eksperimen : descriptive analytic. Pendekatan yang digunakan adalah pendekatan cross sectional pada penelitian ini 
mengetahui apakah ada hubungan dukungan keluarga dengan tingkat kecemasan. Pengumpulan data menggunakan metode Questioner yang bertujuan menganalisa variable bebas dan variable terikat. Pelaksanaan teknik sampling dalam penelitian ini menggunakan total sampling dan mendapatkan sample sebesar 54 responden. Analisis data terdiri dari analisis univariat, dan bivariate. Analisis bivariate menggunakan uji kendal tau.

\section{HASIL PENELITIAN \\ Karakteristik responden \\ Jenis Kelamin}

\section{Tabel 1}

Distribusi Frekuensi Berdasarkan Jenis Kelamin

\begin{tabular}{cccc}
\hline $\begin{array}{c}\text { Jenis } \\
\text { Kelamin }\end{array}$ & Jumlah & Prosentase (\%) \\
\hline Laki & 33 & 61,1 & \\
$\begin{array}{c}\text { Laki } \\
\text { Perempu } \\
\text { an }\end{array}$ & 21 & 38,9 & \\
Total & 54 & 100,0 & \\
\hline Dari & 54 & responden, & jenis
\end{tabular}

kelamin terbanyak laki laki sebesar 33 $(61,1 \%), \quad 21 \quad(38,9 \%)$ responden Perempuan.

Usia

Tabel 2

\section{Distribusi Frekuensi Berdasarkan} Usia

\begin{tabular}{ccc}
\hline Usia & Jumlah & Prosentase \\
\hline Remaja (17- & 0 & $0 \%$ \\
25 tahun) & & \\
Dewasa (26- & 18 & $33,3 \%$ \\
45 tahun) & & \\
$\begin{array}{c}\text { Lansia }(>45 \\
\text { tahun) }\end{array}$ & 36 & $66,7 \%$ \\
$\quad$ Total & 54 & $100 \%$ \\
\hline
\end{tabular}

Dari tabel diatas dapat diketahui bahwa usia paling banyak dari 54 responden yang menderita gagal ginjal kronik terdapat pada lansia $(>45$ tahun), yaitu sebesar 36 responden $(66,7 \%)$.

\section{Analisis univariat}

Distribusi Frekuensi Berdasarkan

Dukungan Keluarga

Tabel 3

Distribusi Frekuensi Berdasarkan Dukungan Keluarga

Dukungan Keluarga Jmlah Prosentase (\%)

\begin{tabular}{ccc}
\hline Baik & 38 & 70,4 \\
Sedang & 15 & 27,8 \\
Kurang & 1 & 1,9 \\
Total & 54 & 100,0 \\
\hline
\end{tabular}

Berdasarkan data di atas, dapat dilihat dari tabel diatas dari 54 responden, mayoritas dukungan keluarga baik sebesar 38 (70,4\%), sedang $15(27,8 \%)$ dan minoritas dukungan keluarga yang kurang sebanyak $1(1,9 \%)$.

Deskripsi Responden Berdasarkan Tingkat Kecemasan

Tabel 4

Distribusi Frekuensi Tingkat Kecemasan

\begin{tabular}{ccc}
\hline $\begin{array}{c}\text { Tingkat } \\
\text { Kecemasan }\end{array}$ & Jumlah & $\begin{array}{c}\text { Prosentase } \\
(\boldsymbol{\%})\end{array}$ \\
\hline Tidak Cemas & 38 & 70,4 \\
Ringan & 10 & 18,5 \\
Sedang & 5 & 9,3 \\
Berat & 1 & 1,9 \\
Panik & 0 & 0 \\
Total & 54 & 100,0 \\
\hline
\end{tabular}

Berdasarkan data di atas, dapat dilihat dari tabel diatas dari 54 responden, mayoritas tingkat tidak cemas sebesar 38 (70,4\%), Tingkat kecemasan Ringan 10 (18,5\%), Tingkat kecemasan Sedang 5 (9,3\%) dan tingkat kecemasan berat $1(1,9 \%)$. 


\section{Analisis Bivariat}

Hasil Analisis Data Berdasarkan Uji Kendall Tau

\section{Tabel 5}

Hasil Analisis Data Berasarkan Uji Kendall Tau Hubungan Dukungan

Keluarga dengan Tingkat

Kecemasan pada Pasien Gagal ginjal Kronis yang Menjalani Hemodialisa

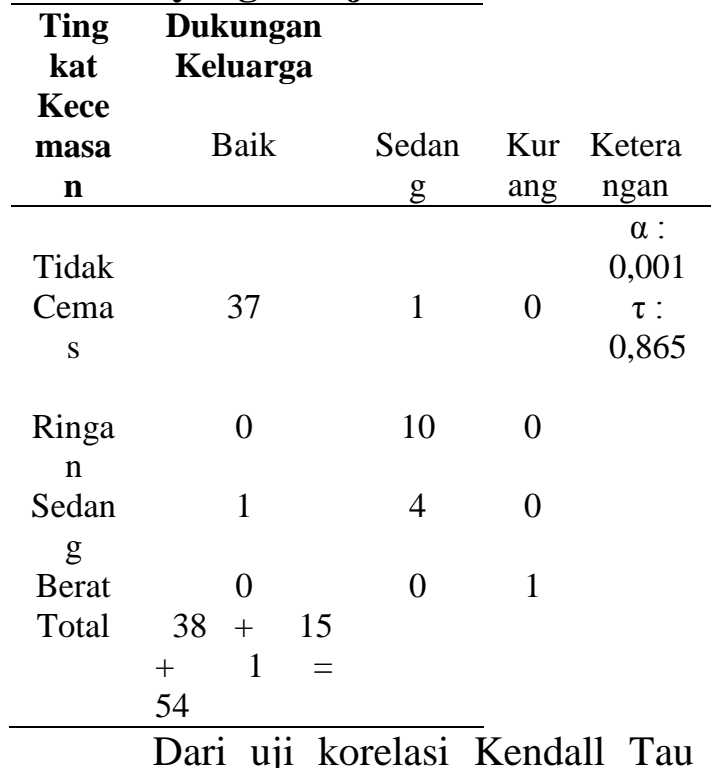

didapatkan $\alpha$ : 0,001, $\rho<0,05$

Terdapat Hubungan dukungan keluarga dengan tingkat kecemasan adalah bermakna dengan kekuatan yang sangat kuat. Didapatkan nila $\tau: 0,865$ korealsi positif dan kuat, artinya semakin tinggi dukungan keluarga semakin tidak ada kecemasan.

\section{PEMBAHASAN}

Keterbatasan dalam melakukan penelitian hubungan dukungan keluarga dengan tingkat kecemasan pada pasien gagal ginjal kronis yang menjalani hemodialisis adalah penelitian berskala kecil dengan jumlah sampel yang sedikit dan hanya di satu rumah sakit. Sehingga, penelitian ini belum dapat digeneralisasikan.

\section{KESIMPULAN DAN SARAN}

Dukungan keluarga pada pasien gagal ginjal kronis yang menjalani terapi hemodialisis mayoritas baik dan minoritas dukungan keluarga yang diberikan kurang.

Tingkat Kecemasan pada pasien gagal ginjal yang menjalani terapi hemodialisis mayoritas dengan tingkat tidak cemas.

Ada hubungan yang bermakna antara dukungan keluarga dengan tingkat kecemasan pada pasien gagal ginjal kronis yang menjalalani terapi Hemodialisis.

Hasil penelitian ini diharapkan dapat menjadi data dasar dalam mengkaji dan mempelajari tentang pentingnya keluarga dalam memotivasi pasien untuk menurunkan tingkat kecemasaan khusunya pada pasien gagal ginjal yang melakukan cuci darah.

Memotivasi keluarga pasien yang belum termotivasi diharapkan untuk memfasilitasi dalam meningkatakan dukungan antara keluarga dengan pasien pada saat melakukan terapi hemodialisis dengan melibatkan keluarga, dalam menjalani terapi pengobatan yang dilakukan pasien.

Bagi keluarga diharapkan dapat selalu terlibat dalam membentuk hubungan yang harmonis dengan pasien gagal ginjal kronis yang melakukan Hemodialisis.

Bagi Peneliti selanjutnya sebaiknya melakukan penelitian dibeberapa rumah sakit tidak hanya satu rumah sakit, sehingga hasil penelitian diharapkan mampu digeneralisasikan di penelitian dunia. 


\section{DAFTAR RUJUKAN}

Afiatin. (2014). Simposium Dialisis Indonesia Renal Registry. Retreived from http://ipdi.or.id/materi\%20toni/ baru/3.\%20dr.\%20Afiatin\%20 \%20IRR\%20simpondilaiisis.pdf

Arikunto, S. (2010). Prosedur Penelitian. Jakarta: Rineka Cipta.

Departemen Kesehatan RI. (2011). Profil Kesehatan Indonesia 2011. Tersedia di http://www.depkes.go.id/downl oads/publikasi/ProfilKesehatanI ndonesia2011.pdf.

Desi (2014). Hubungan Dukungan Keluarga Dengan Tingkat Depresi Pasien Gagal Ginjal Kronis Dengan Hemodialisis di RS PKU Muhammadiyah Yogyakarta.

Dinas Kesehatan RI. (2009).Buku Profil Kesehatan Provinsi Jawa Tengah Tahun 2012. Semarang: Dinkes Jateng

Friedman, M.M. 2010. Keperawatan Keluarga:Teori dan Praktek. Jakarta:EGC

Hamilton, M. (1959). Hamilton Anxiety Rating Scale (HAMA).://pdbp.Ninds./Hamilton/An xiety/Rating/Scale(HAMA).pdf.

Hartono, Marsito, dan Azti (2009). Hubungan Antara Dukungan Sosial Keluarga Dengan Tingkat Kecemasan Pasien Rawat Inap di RSU PKU Muhammadiyah Gombong. Retrieved from https://books.google.co.id/book $\underline{\text { s?id=i9mAClWMwKIC\&prints }}$ ec=frontcover $\& h \mathrm{l}=\mathrm{id}$

Haryono R. (2013). Keperawatan Medikal Bedah : Sistem
Perkemihan. Yogyakarta : Rapha Publishing.

Hidayat, A \& Azis, A. (2009). Metode Penelitian Keperawatan dan Teknik Analisis Data. Jakarta: Salemba Medika.

Hudak, C.M. \& Gallo, B.M. (2012). Keperawatan Kritis Pendekatan Holistik. Volume II Edisi VI. Jakarta: EGC

Iin A. (Juni, 2014). Analisis Perubahan Status Fisiologi Jantung Pada Pasien Yang Dilakukan Hemodialisa Di RSUD Dr. Moewardi Surakarta. Skripsi Dari Politeknik Kesehatan Surakarta.

Jeffrey, S, Spencer A \& Beverly, G (2006). Psikologis Abnormal edisi 5. Jakarta : Erlangga.

Kementerian Kesehatan RI. (2013). Riset Kesehatan Dasar (RISKESDAS) 2013. Retrieved from

http://www.depkes.go.id/resour ces/download/general/ Hasil\%20Riskesdas\%202013.p df

Kusuma, H (2011). Hubungan antara Depresi dan Dukungan Keluarga dengan Kualitas Hidup Pasien HIV/ AIDS yang Menjalani Perawatan di RSUPN Cipto Mangunkusumo Jakarta. http://lib.ui.ac.id/file?file=digita 1/20282772-T-

Henni\%20Kusuma.pdf diakses tanggal 1 Februari 2016.

Kusumawati, F., \& Hartono, Y. (2010). Buku Ajar Keperawatan Jiwa. Jakarta : Salemba Medika.

Liandi (2011). Hubungan Dukungan Keluarga Dengan Tingkat Kecemasan Pre Operasi Pada 
Anak Usia Sekolah di RS PKU Muhammadiyah Yogyakarta.

Mary, C. (2010). Diagnosis Keperawatan psikiatri Edisi 5. Jakarta : EGC

Mustika, Ana. (2015).Hubungan Dukungan Sosial Keluarga Dengan Tingkat Kecemasan Pasien Gagal Ginjal Kronis di RSUD Dr. Moewardi Surakarta.

Nevid, Rathus, dan Greene, B. (2006). Dalam Buku Psikologi Abnormal Edisi Kelima Jilid 1.Jakarta : Erlangga.

Nurpeni. (2013). Hubungan Dukungan Keluargadengan Tingkat Kecemasan Pada Pasien Kanker Payudara di Ruang Angsoka III RSUP Sanglah Denpasar. Bali.

Nursalam. (2014). Metodologi Penelitian Ilmu Keperawatan : Pendekatan Praktis, Edisi 3. Jakarta : Salemba Medika.

Perhimpunan Dokter Spesialis Penyakit dalam Indonesia. (2009). Buku Ajar Ilmu Penyakit Dalam Jilid II Edisi V. Jakarta : Interna Publishing.

Potter, P.A., \& Perry, A.G. (2010). Fundamental Keperawatan, Buku 2, Edisi 7. Jakarta : Salemba Medika.

Prabowo, E. (2014). Buku Ajar Keperawatan Jiwa. Yogyakarta
Price S.A \& Wilson L.M. (2005). Patofisiologi : Konsep Klinis Proses- Proses Penyakit. Edisi 6. : Jakarta : EGC

Sheila, L. (2008). Buku Ajar keperawatan Jiwa Edisi 1. Jakarta : EGC

Smeltzer, S.C., \& Bare, B.G. (2002). Buku Ajar Keperawatan Medikal - Bedah Brunner \& Suddarth, Edisi 8, Volume 2. Jakarrta : EGC.

Struart, G. W (2007). Buku Saku Keperawatan Jiwa Edisi 5.Jakarta : EGC

Sugiyono. (2010). Statistik Untuk Penelitian. Bandung : CV.Alfabeta.

Suwitra, K. (2009). Penyakit Ginjal Kronik, dalam Sudoyo, A.W., Setiyohadi, B., Alwi, I., K, M. S., \& Setiati, S (Eds), Buku Ajar Ilmu Penyakit Dalam, Edisi Kelima, Jilid II. Jakarta : Interna Publishing.

Zurmeli. (2015). Hubungan Dukungan Keluarga dengan Kualitas Hidup Pasien Gagal Ginjal Kronik yang Menjalani Terapi Hemodialisis di RSUD Arifin Achmad Pekanbaru. Retrieved from http://jom.unri.ac.id/index.php/ JOMPSIK/article/download/517 $\underline{2 / 5052}$ 